\title{
Arte contemporânea: do que se trata? Notas feitas através da leitura do livro The contingent object of contemporary art de Martha Buskirk
}

\author{
PÉROLA MATHIAS
}

\section{Resumo}

O que designa exatamente aquilo que chamamos de "arte contemporânea” nos dias atuais? Essa expressão é um rótulo estético, um estilo, um gênero, um período histórico ou o quê? A respeito de certos artistas argumentarem que faz arte contemporânea aquele que produz arte no seu tempo presente, este texto busca deslindar a complexidade de questões sobre este "paradigma" artístico através da leitura do livro The contingent object of contemporary art de Martha Buskirk. A autora, além da

Palavras-chave: Arte contemporânea, autoria, obra de arte problematização sobre a contingência do objeto, traz questões acerca da autoria, originalidade e inserção dos novos modos de produção e fruição no mundo da arte. 


\title{
Contemporary art: what is it about? Notes taken through the reading of the book "The contingent object of contemporary art" written by Martha Buskirk
}

\author{
PÉROLA MATHIAS
}

\begin{abstract}
What does exactly mean that thing that we use to call "contemporary art" nowadays? Is this expression an aesthetic label, a style, a genre, a historic period or what? Concerning the argument of certain artists that the one who works in your own present time can make contemporary art, this text seeks to explain the complexity of questions about this artistic "paradigm" through the reading of the book "The contingent object of contemporary art" written by Martha Buskirk. The author, besides the problematization of the contingency of the object, brings questions about authorship, originality and insertion of new production methods and fruition in the world of art.
\end{abstract}

Keywords:

Contemporary art, authorship, work of art 


\title{
Arte contemporáneo: ¿De qué se trata? Notas hechas a través de la lectura del libro The contingent object of contem- porary art de Martha Buskirk
}

\author{
PÉROLA MATHIAS
}

\section{Resumen}

¿Qué designa exactamente aquello que llamamos de "arte contemporáneo" en los días actuales? ¿Esa expresión es un rótulo estético, un estilo, un género, un período histórico o lo qué? Con relación a ciertos artistas argumentaren que hacen arte contemporáneo aquel que produce arte en su tiempo presente, este texto procura deslindar la complejidad de cuestiones sobre este "paradigma" artístico por medio de la lectura del libro The contingent object of contemporary art de Martha Buskirk. La autora, además de la problematización

Palabras clave: Arte contemporáneo, a utoría, obra del arte sobre la contingencia del objeto, trae cuestiones acerca de la autoría, originalidad e inserción de los nuevos modos de producción y fruición en el mundo del arte. 
$\boldsymbol{F}_{\text {requentemente ao serem perguntados sobre o que é arte }}$ contemporânea, artistas respondem prontamente que é a arte do seu tempo, correspondente ao trabalho que realizam no tempo presente. Assim, todos os artistas que coexistem em um mesmo tempo histórico, o do agora, são contemporâneos, independente de estilo. Foi assim que a artista brasileira Adriana Varejão falou a respeito de seu trabalho no dia do lançamento do livro Pérola imperfeita: a história e as histórias na obra de Adriana Varejão ${ }^{1}$, ao comentar sobre tentativa de pensá-la como uma artista de arte contemporânea.

A resposta de Varejão parece legítima no sentido de que a artista possa ter tentado escapar dos rótulos que tentam definir e enquadrar uma produção ampla e heterogênea como a dela e, sobretudo, de enquadrar em um único formato um trabalho cujo processo de criação é fundamentalmente amparado na liberdade e criatividade - ou é assim, ao menos, a tradicional definição do trabalho artístico ou do sistema da arte.

Apesar de a resposta de que faz arte contemporânea aquele que vive seu tempo ter sido uma boa saída, ela fica de certa forma alheia a uma série de questões que perpassam o "desenvolvimento" da arte, do trabalho artístico e da posição de artista. O que fez surgir a "arte contemporânea"? Esta expressão é um rótulo estético, um estilo, um gênero, um período histórico ou o quê?

Martha Buskirk, historiadora da arte e crítica, professora da Montserrat College of Art de Massachussets nos Estados Unidos desde 1994, no livro The contingent object of contemporary art, demonstra algumas das principais questões e características que giram em torno do debate sobre a arte contemporânea. O que torna a discussão em torno do tema um pouco mais densa, visto que traz elementos para questionamento do que parece ser um "paradigma" para pensar e fazer arte no tempo presente - ao invés 
de buscar uma gênese de algo que ainda tentamos entender e situar no tempo histórico. A principal das questões levantadas por Buskirk é a transformação de concepção em que a obra de arte não mais corresponde, necessariamente, a um objeto material, tal como concebemos até o que se entende por arte moderna. Na arte contemporânea, o objeto material como obra de arte compartilha seu posto com ideias, performances, documentações visuais fotográficas, videográficas, projetos ou intervenções, planos de execução, site-specifics, dentre muitas outras opções.

Esta transformação quanto ao que pode constituir uma obra e as inúmeras possibilidades a serem adotadas pelo artista quanto ao formato, meio, contexto, conteúdo, aparência, duração, ambientação, etc., complexifica as escolhas e torna evidente a mudança de status da obra de arte. E aí está uma das principais características do que se chama arte contemporânea: a multiplicidade e heterogeneidade de materiais e meios que podem constituir um trabalho artístico.

Martha Buskirk pontua que alguns precedentes históricos abriram essa possibilidade. Em primeiro lugar, desde a entrada do século XX se fala em uma suposta crise da arte devido ao desenvolvimento e crescimento dos meios técnicos de reprodução, em que todo objeto artístico, assim considerado por causa de sua unicidade e originalidade, pode ser reproduzido de alguma forma com o avanço da técnica do meio industrial e de recursos como a fotografia e o cinema - também tornadas arte. A implicação da possibilidade da reprodução técnica, segundo escreveu Walter Benjamin (BENJAMIN, 2012), autor também citado pelo livro, é a perda da "aura" da obra de arte, o seu "aqui-e-agora". Ou seja, a perda do sentimento experienciado quando estamos defronte do exemplar original e único de uma obra de arte. Com o desenvolvimento dos meios técnicos, da fotografia e do cinema, há a ampla possibilidade de acesso de um número muito maior de pessoas a uma obra através de suas reproduções.

Em segundo lugar, a autora coloca que há o precedente histórico do readymade, conceito criado pelo artista francês Marcel Duchamp. O conceito de trabalho iniciado por Duchamp é o desafio que foi posto aos novos artistas, retrabalhado e retomado diversas vezes como "paradigma". A ideia descreve trabalhos de arte que foram feitos selecionando e designando objetos cotidianos (industrialmente produzidos), escolhidos justamente por causa de sua familiaridade. O conceito de readymade ficou conhecido depois da ação de 
Duchamp da proposta da obra A Fonte, um urinol branco de louça assinado pelo artista com o nome da indústria que o produziu, $R$. Mutt, que foi enviado como trabalho artístico em 1917 para exposição no Le Salon des indépendances.

$\mathrm{O}$ readymade descreve trabalhos de arte feitos simplesmente pela seleção e designação, como obra de arte, de objetos cotidianos que não foram construídos para fins artísticos, segundo as convenções e materiais comuns a este meio.

Uma interessante análise é feita pela socióloga francesa Nathalie Heinich (HEINICH, 2014), que defende que o readymade se tornou um emblema da arte contemporânea, tendo surgido num período em que a arte moderna se tornava o novo paradigma da história da arte. E ele é considerado uma obra não pela materialidade do objeto apresentado como tal, mas pelo ato de propô-lo enquanto obra em uma exposição. Daí, Heinich desdobra algumas transformações na obra de arte que caracterizam o que se chama "arte contemporânea". A obra de arte não é mais, ou não é mais necessariamente, um objeto material produzido pelo artista, mas se torna principalmente o "contexto, as palavras, as ações, coisas, números" (HEINICH, 2014). Ou seja, a ênfase antes dada à apreciação estética do objeto se volta para novos tipos de procedimentos, e a atividade do fazer artístico passa a incorporar materiais e métodos vindos de outras disciplinas. Convergindo sua posição com a socióloga citada, Martha Buskirk sinaliza que, com esta transformação, algumas questões paradoxais aparecem através das muitas formas da arte contemporânea, e elas dizem respeito a pares conceituais como: original/cópia; performance/documento; objeto/contexto; representação/abstração; permanência/transitoriedade, que encaram um contínuo processo de redefinição.

A Fonte é considerada um marco nesse processo porque, além de ser o exemplo mais conhecido do readymade de Duchamp, abriu precedentes para que uma ilimitada variedade de manifestações adentrasse o museu. Desta situação deriva um gesto múltiplo que envolve o ato de selecionar um objeto dentre vários e designá-lo como um trabalho de arte - ou seja, colocá-lo sob o signo da ideia e do trabalho de uma pessoa. É possível afirmar que o museu, no período pós-moderno, como propôs Andreas Huyssen (1997), ocupa uma posição de autoridade cultural, mas a instituição sofre também uma transformação que supera a dialética museu/modernidade. Ele não é mais apenas o guardião de artigos que representam o passado histórico, antes exibidos apenas para um grupo apto a compreendê-los, 
mas passou a adentrar o mundo dos espetáculos de diversão de massa, ser o lugar do novo, do agora e de simulação do futuro.

A mudança no status da obra de arte percebida pelos dois precedentes históricos, que constituem um dos prismas pelos quais podemos ver a arte contemporânea, traz ainda outras questões para o mundo da arte. Com o desenvolvimento dos meios técnicos de reprodução adentrando o fazer artístico, uma das características centrais da arte é atingida. Se a arte é um sistema baseado na originalidade e autenticidade de obras geradas por indivíduos, ao utilizar objetos materiais industrialmente produzidos e designá-los como arte, é excluído o toque manual do artista que legitima a autoria do objeto como obra. Assim, o que passa a caracterizar a autoria de uma obra? Como ela é controlada? Do mesmo modo, como avaliar o que torna uma obra de arte original? Quais os critérios de avaliação que passam a fazer parte da organização artística?

Por fim, outro aspecto central na arte contemporânea é aquele que dá título ao livro de Buskirk: a contingência do objeto artístico. Como aborda a autora, a ênfase na ideia ou conceito explicita a possibilidade da obra de arte não ser mais sinônimo de "objeto". Os trabalhos de arte expandiram a estrutura física tradicional do museu e em muitos casos os artistas aproveitaram as configurações que lhes permitem criar obras não imediatamente identificáveis como arte.

Das questões levantadas e discutidas por Martha Buskirk, entendo que a autoria, a originalidade e a contingência do objeto da arte contemporânea são chaves para compreensão da discussão contida no livro. E dentro destas três questões chaves, algumas características apreendidas na arte contemporânea se repetem: a abstração da materialidade da obra de arte; o tipo de material utilizado; a dificuldade de se lidar com a possibilidade da cópia, suas implicações legais e de mercado; a importância do ambiente em que uma obra é realizada/exposta (seu contexto); e a constante referência à história da arte ou ao tempo passado de forma geral. É pautando-me nestas três questões e suas características comuns, absorvidas principalmente da leitura da autora citada - Martha Buskirk -, que tentarei abordar uma visão sobre a arte contemporânea.

\section{Autoria, originalidade e contingência}

Em seu livro, Martha Buskirk elenca as principais questões da arte contemporânea. Para ela, essas questões são: autoria e autoridade; o original e as cópias; o meio e a materialidade; 
o contexto como sujeito; e a contingência. A discussão de todas essas características são iniciadas pela autora ao longo dos capítulos por meio de exemplos da história da arte contemporânea, moderna e vanguardista. Através da apresentação dos casos é que Buskirk vai engrossando sua análise e demonstrando suas hipóteses e constatações.

Apesar da separação dos capítulos, as características que cada um aborda estão interconectadas ao longo de todo o texto. E três delas me pareceram sobressair: a autoria, a originalidade e a contingência, que são questões que, de forma geral, sempre permearam o sistema da arte. As mudanças no meio, na materialidade e no contexto de realização das obras estão intrinsecamente relacionadas ao status da autoria, da originalidade e da contingência. Com a suposta ausência da mão do artista da obra produzida, Buskirk defende que ao invés de acabar a relação entre obra e autor, a relação é reorganizada de outra forma, tornando a autoria artística ainda mais significante nos trabalhos contemporâneos.

A abertura da possibilidade de explorar o fazer artístico a partir de qualquer ideia é um dos mais significativos desafios colocados à arte até o final do século XX, deixando de lado a necessidade de se configurar alguns limites para o que poderia ser definido como a arte - ou ao menos alguns parâmetros para se reconhecer o que pode vir a ser arte. Pois, sem novos parâmetros para repensar os meios pelos quais as obras são apresentadas, a lida com esse novo status da obra de arte seria abordar o incomensurável.

\section{O minimalismo}

Entre a década de 1960 e 1970 surgem correntes artísticas como o minimalismo e a arte conceitual. Ambas, dizendo de forma muito genérica, enfatizavam a abstração da materialidade da obra de arte. Os 40 anos passados desde o surgimento dessas movimentações até o fim do século XX caracterizam para Burskirk o período em que quase tudo pode ser e tem sido considerado como arte, sinalizando que essa abstração está ligada à pluralidade de métodos do fazer artístico. E essas movimentações são, de alguma forma, uma retomada histórica e uma reatualização do desafio colocado pelo readymade.

O readymade erradicou a pintura como uma arena específica da exploração artística. A partir daí, questiona-se qual será e como se concretizará o meio de apresentação da obra. Com o fim do século XX, categorias clássicas como pintura, escultura 
ou fotografia foram perdendo sua exclusividade e seu status de marcas autoevidentes do meio e do suporte material da obra.

No minimalismo, os trabalhos se caracterizavam pelo uso de materiais industriais, por uma aparente simplicidade na apresentação de formas geométricas, pela repetição dessas formas e pela ativação do espaço que rodeia a obra como fundamental para que fosse compreendida pelo seu espectador. No entanto, esses trabalhos excluíam o toque do autor no momento de produção da obra.

A enganosa simplicidade que inspirou o rótulo de minimalismo levantou uma discussão sobre se os artistas se concentravam na forma ideal em detrimento da realização material específica, ou se o ponto não era exatamente a execução de uma forma específica, mas um rearranjo de todo o contexto em que a obra de arte pode estar envolvida: o meio em que é apresentada, o material utilizado, a ideia de projeto que a tornará possível.

Como nomes identificados ao minimalismo, Buskirk cita exemplos de artistas como Donald Judd e Dan Flavin. O primeiro, que ganha destaque na análise da autora, publicou em 1990 um anúncio na revista Art in America dizendo que uma instalação exibida na Ace Gallery de Los Angeles estava com a autoria erroneamente atribuída a sua pessoa, pois a fabricação da peça para a exposição havia sido autorizada apenas por Giuseppe Panza, o colecionador que comprou o direito da obra.

A instalação em questão consistia numa parede de placas de metal galvanizado. $\mathrm{O}$ material da obra não viabilizava a sua movimentação de um lugar de exibição para outro, visto o peso e a dificuldade de transporte. Por ser uma instalação, foi desenvolvido um plano de montagem da obra para que ela pudesse ser exposta, documento que foi vendido ao colecionador como sendo a obra.

Um trabalho feito pelo ato de designação ou fabricação de um objeto na base de instruções levanta questões sobre quais aspectos da autoria são transferidos para o colecionador ou instituição que compra aquele trabalho. Quem tem a autoridade de realizar um trabalho que se baseia em planos? Uma vez que a ideia do readymade foi estabilizada como um modelo que permite ao artista pegar um objeto e designá-lo como uma obra autoral, qual a medida de sua autoridade sobre o objeto e sua transmissibilidade?

Panza é um dos mais proeminentes colecionadores da arte moderna, incluindo o minimalismo e a arte conceitual. Buskirk relata muito dos problemas ocorridos nas relações travadas 
entre ele e artistas como Dan Flavin, Robert Morris, Bruce Nauman, Carl Andre e com o próprio Judd por inúmeras vezes.

Sobre Judd e Panza, Buskirk demonstra que uma parte importante do problema entre eles estava na linguagem dos certificados oficializados pelos dois, em que Judd contribuiu assinando os contratos sem ter total consciência de todas as cláusulas de transferência, levando Panza a pensar na autoria da obra como um poder legalmente definido e transferível, ao invés de um gesto inato do artista. Nesse caso, a relação de compra, venda e transmissão de poder para que uma obra seja executada por meio de seu plano de concepção, assim como a relação entre artista e comprador, se torna muito complexa, diferente de uma compra em que um objeto é transmitido da posse de seu autor para um comprador.

Sobre os problemas que Judd e Panza tiveram quanto às aquisições e exibições, Buskirk chega a citar uma declaração de Judd em que ele diz, ironicamente, ao ver uma de suas obras montadas por Panza sem o seu consentimento, que Panza não era um bom artista.

A linguagem crítica, a linguagem declarativa, a linguagem das instruções, dos acordos e contratos, todas elas são relevantes porque moldam a forma pela qual um trabalho de arte vai chegar ao espectador. Ou seja, é desses contratos e planos formalizados que dependem o arranjo, a disponibilidade e a montagem da obra de arte conceitual para uma exposição. Bem como para definir a natureza e limitar os trabalhos artísticos, estabilizando uma obra de arte no tempo.

Esse caso sobre autoria demonstra também uma interseção entre autoria e propriedade, que se refere à conexão contínua (ou não) do artista com seu trabalho, expressa nos esforços em controlar contexto e localização e implicando exigências legais para colecionadores e instituições em consultar o artista. No entanto, a consulta depende daquilo que ficou acertado nos certificados, contratos e instruções que acompanham o trabalho. Mas como se desdobra essa dependência? A colocação de um trabalho que o artista já não possui está ou não fora de seu controle?

Outro problema é lembrado por Buskirk quando ela analisa que a história da arte é cheia de exemplos em que os artistas retornam a obras do passado e reinterpretam suas ideias. A questão aí é o que constitui a diferença entre a reinterpretação e a simples repetição, a qual o artista está ou não autorizado a realizar dependendo do certificado de singularidade e unicidade que outrora ele tenha atribuído a uma obra vendida por 
contrato. Pois os costumes do mundo da arte, dirigidos pelo mercado da raridade, insistem na distinção entre um trabalho único e um trabalho produzido em edições. A convenção da "edição limitada" foi desenvolvida em resposta à multiplicidade inerente na reprodução mecânica, que é oposta à singularidade de uma obra original pintada à mão, por exemplo.

A autoria continua sendo um tópico importante porque há um corpo de leis que falam pela integridade da obra de arte baseada nesta categoria e na crença de que o trabalho de arte é mais do que apenas uma "comodity". Quando um trabalho de arte é feito usando formas próximas ou idênticas a de objetos definidamente não artísticos, a designação de autoria pode ser a única característica que distingue arte de "não-arte".

E o que foi possível observar sobre a transformação da arte desde o readymade de Duchamp, e depois com os movimentos artísticos surgidos na virada da década de 1960, é a percepção que se tem do objeto. O uso de formas e materiais industriais padronizados contribuiu para que a obra tenha uma aparência de não-arte, fazendo com que as características e qualidades da obra sejam destacadas com uma "ativação poderosa da exterioridade do desdobramento fenomenológico da experiência do espectador no tempo e no espaço". E assim toda nuance de interseção do objeto, do espaço ao redor e da experiência do espectador assume uma grande importância.

Burskirk diz que "um antigo ideal de unidade entre forma e conteúdo pressupõe um processo de criação em que as discussões sobre forma eram inseparáveis do ato de produzir o trabalho, com o trabalho emergindo do estúdio já realizado e autossustentado". Com os trabalhos que são completados não no estúdio, mas apenas no lugar de sua exibição ou espaço de performance, sua existência está relacionada à sua apresentação pública; como o momento da exposição e encontro com o espectador, que constitui a "experiência fenomenológica", visto que essa depende da percepção do espectador.

A interpretação do objeto não é simplesmente questão de uma possível resposta variada para um objeto físico essencialmente estável. Mas, em vez disso, uma etapa prévia de interpretação pode ter dramáticas implicações para a configuração do objeto a ser percebido. Hal Foster, um crítico citado pela autora, defende que o minimalismo não pode ser visto sob a ótica de um movimento pautado na busca de uma forma ideal, pois estabelece a diferença entre a "pureza de concepção" e a "contingência da percepção". As bases artísticas que o movimento postula para a arte contemporânea aproximam-se da 
ideia de "morte do autor" e "nascimento do espectador", discutida por Roland Barthes, também citado pela autora.

Para Barthes, a construção da personagem do "autor" é uma criação da sociedade moderna que descobriu o prestígio pessoal do indivíduo. Na figura do autor, a literatura moderna encontra sua imagem: sua pessoa, seus gostos, sua história, etc. As tentativas de inversão desse papel buscam alternativas para a linguagem escrita, como a via de Mallarmé de focar na impessoalidade da escrita, de encontrar o ponto em que as palavras performam o texto sem identificar o traço da pessoalidade daquele que o realiza. Para Barthes, "dar um autor a um texto é impor a esse texto um mecanismo de segurança, é dotá-lo de um significado último". No entanto, um texto, assim como uma obra de arte, por mais que se tenha a ideia de unidade da obra presa à autoria de quem a compõe, pode ser visto como uma escrita múltipla, um símbolo com significados ambíguos,

assim se revela o ser total da escrita: um texto é feito de escritas múltiplas, saídas de várias culturas e que entram umas com as outras em diálogo, em paródia, em contestação; mas há um lugar em que essa multiplicidade se reúne, e esse lugar não é o autor, como se tem dito até aqui, é o leitor [...] a unidade de um texto não está na sua origem, mas no seu destino, mas este destino já não pode ser pessoal (BARTHES, 2004).

Barthes (2004) desloca aquilo que, nas artes plásticas, se considera a unidade da obra vista pela confirmação da autoria para o receptor: por múltiplas que sejam os significados e percepções, ele se dá num único "lugar", o leitor/espectador. É no espectador que a obra se realiza.

No caso das obras minimalistas, o grau em que os traços tradicionais da presença do artista foram removidos do trabalho pode ser conectado a características significantes da autoria descrita também por Michel Foucault (autor também citado por Burskirk) como um sistema de classificação baseado no uso do nome do autor para designar e diferenciar trabalhos.

Para Foucault (2006), o nome do autor é diferente do nome próprio da pessoa que está por trás do produto. Esses dois "nomes" ficam separados em dois polos: o da descrição e o da designação. Eles têm certa ligação com o que eles nomeiam, mas não uma ligação específica. Ou seja, para Foucault, "um nome de autor não é simplesmente um elemento em um discurso [...] ele exerce certo papel em relação ao discurso: assegura uma função classificatória" (FOUCAULT, 
2006, p. 273). O que quer dizer que uma relação de filiação é criada para com o trabalho. $\mathrm{O}$ nome do autor funciona para caracterizar certo "modo de ser do discurso", referindo-se ao status desse discurso em uma sociedade e cultura específicas. A função de autor para Foucault, sendo um modo de existência, é também a forma de fazer circular e funcionar certos discursos dentro de uma dada sociedade. $\mathrm{O}$ autor pensa que "grandes unidades discursivas" funcionam em um determinado sentido, assim seria a criação do nome de autor. Assim, também, penso que seriam grandes rótulos, como o próprio nome de "minimalismo" ou de "arte contemporânea".

\section{O problema das cópias}

A transformação artística operada pela arte moderna foi ter buscado novas formas estéticas. A pintura dos expressionistas abstratos no pós-guerra, visto os meios e os gêneros em que se pautaram, era ultrapassada em suas ambições se pensarmos que, mesmo que eles tenham extinguidos a figuração, o suporte continuava em muitos casos o mesmo. Já a arte contemporânea passa por uma ruptura das formas materiais.

Metodologicamente, Burskirk se recusa a enxergar o afastamento da unidade do meio e da forma associadas à arte moderna como uma consequência impremeditada da noção de uma ruptura "pós-moderna". A aceitação da arte contemporânea pelos museus, galerias e colecionadores, não é porque essas instituições estão focadas no cuidado e preservação da unicidade das obras de arte, ainda que a parte da documentação e preservação ainda exerça forte influência na ação das instituições e na transformação cultural do como lidar com a arte. Buskirk assegura que, desde o começo dos anos 1990, tem sido difícil imaginar o que não pode adentrar o espaço de um museu de arte. As definições e convenções institucionais iniciadas nos anos de 1960 e 1970 ajudaram a estabilizar a possibilidade de uma efêmera instalação:

A fascination with the rhetoric of exhibition display, an analysis of the conditions established by different types of contexts, the transformation of the space, and even the decision to move outside such spaces are all aspects of this play with the nature of the presentation itself. The analysis of institutional practices has also found expression in the creation of works where the collecting process is part of the artist's method, or where there is an explicit focus on the history of the object. As part of this 
process the art museum has also become a forum for work with an explicit political agenda (BUSKIRK, 2003, p. 164). ${ }^{2}$

O contexto em que um trabalho é criado passa ser intrínseco a ele. E enquanto o trabalho muda, as práticas das instituições tentam acompanhá-lo. A origem, ou de onde provém um trabalho, passa a ser uma importante ferramenta para confirmar sua autenticidade.

O readymade de Duchamp foi uma crítica violenta à tradição artística, baseado especificamente no fato de que os objetos que ele selecionou e depois designou como sendo a obra não eram nem originais, nem raros. E mesmo assim ele se tornou alvo dessas instituições tradicionais. Seus objetos não foram selecionados por sua qualidade artística, mas eram manufaturados, produzidos em série, com a forma predeterminada. E justamente por serem objetos que provocam certa indiferença visual e, ao mesmo tempo, uma indiferença quanto ao bom gosto ou ao mau gosto, é que eles chamaram a atenção de Duchamp. Buskirk aponta que a ideia de Duchamp, segundo ele mesmo dizia, era mostrar a completa anestesia em que a sociedade de seu tempo vivia com relação à indústria de massa e à lógica do consumismo.

Nas décadas de 1980 e 1990, alguns artistas produziram obras que faziam referência direta e explícita à Fonte de Duchamp. Uma delas foi Sherrie Levine com a obra "Fontain (after Duchamp)", um urinol esculpido em bronze fundido, de 1991. A obra de Levine é um exemplo minuciosamente analisado pela autora e demonstra uma série de questões. A primeira que ela tenta explicar é o "por quê" e "como" é possível que, ao se mostrar um urinol, ou um objeto com forma parecida, a referência a Duchamp é incontestável e explícita. Todo estudante de arte sabe que o urinol utilizado segundo o conceito de readymade vem com um "nome próprio" (proper name), atrelado a ele, o de Duchamp. E, no entanto, cada artista que tenha se referenciado a um urinol em uma obra de arte no século XX realizou a façanha paradoxal de reivindicar autoria sobre a peça. $O$ fato de o nome de Duchamp estar atrelado a qualquer uso de objetos como uma roda de bicicleta, uma pá de neve e especialmente ao urinol em contextos que não aqueles para o quais esses objetos foram desenvolvidos, deu-se pela construção de um discurso histórico artístico legitimado pela entrada do autor, com estes objetos, em exposições e coleções de museus.

Segundo a autora, o interesse de Levine em Duchamp veio no meio de uma nova onda de interesse em formas de cópia e 
simulação durante a década de 1980, a qual era dado o rótulo de "arte apropriação" (label of appropriation art). O readymade de Levine, na verdade, é uma transmutação ou uma subversão do conceito de Duchamp, que trazia um poder transgressor no ato de simplesmente selecionar um objeto da produção de massa como obra. Já Levine, ao invés de usar um objeto manufaturado como representação, criou, ela mesma, um objeto semelhante utilizando material e métodos próprios às belas artes: ao invés de um urinol de louça, direto da fábrica, ela moldou um urinol em bronze, que também poderia ser reproduzido infindamente com um molde.

Buskirk cita a teoria da vanguarda de Peter Bürger para analisar a referência à história da arte que aparece em obras como a de Levine. Para este autor, a "nova vanguarda" institucionalizou os movimentos de vanguarda (modernas) como arte, como o dadaísmo, ao qual Duchamp é identificado, para depois negar as intenções dos vanguardistas. Bürger reconhece que o objeto proposto como antiarte perde seu caráter e se torna um autêntico objeto de arte ao adentrar o museu e ser colocado ao lado das demais obras autônomas.

Os objetos mais originais que Duchamp selecionou como readymades foram perdidos e não foram repostos até décadas depois da proposição do artista, até que um processo retroativo de recontextualização e reconstrução tomou parte numa nova produção iniciada por Duchamp: o projeto da Caixa-Valise, de 1941. A Caixa-Valise consistiu na publicação de reproduções e fac-símiles de seus trabalhos, bem como de notas relacionadas a eles. Com esse projeto, Duchamp conseguiu assegurar a continuidade da existência de seus readymades como conceitos, mesmo que o objeto físico estivesse perdido.

Com este ato, os readymades primeiramente propostos como a escolha referenciada de um objeto de produção de massa, passam a ter seu status de arte garantido, sofrendo uma grande transformação em seu conceito.

As "cópias" do readymade aparecem como base para uma concepção do fazer artístico em que os artistas incorporam referências à história da arte sem necessariamente se ater a suas técnicas ou materiais. Burskirk menciona a obra de Sherrie Levine junto com outros exemplos, como os de David Hammons e Robert Gober, mostrando como a utilização da mesma referência à Fonte de Duchamp pelos artistas levou à criação de obras tão diversas entre si. Isto porque o contexto ao qual se associa cada uma vem de uma reflexão prévia no trabalho desses artistas. No caso de Levine, ela utiliza o urinol, um objeto 
masculino com formas que se assemelham às formas femininas, como parte de uma reflexão sua sobre a questão de gênero nos movimentos de vanguarda. Além dessa reflexão, ela insere assuntos de uma pauta ou agenda política contemporânea na arte (como gênero, sexualidade, liberdade do corpo, etc.), muito conectados com as formas discursivas com que esses temas são tratados hoje.

No caso do urinol, a exploração da forma escultural desenha uma obra que é parecida com a obra referenciada, mas não é mesma e nem se configura como uma cópia, porque houve por parte da artista a super elaboração de um contexto para recepção de sua obra. Assim, Burskirk analisa que o "quase-mesmo" (almost same) se torna o radicalmente diferente "quando mudanças pequenas ou mesmo insignificantes na forma ou na imagem reproduzida acompanham as mudanças dramáticas no contexto da recepção da obra" (BURSKIRK, 2003, p. 65).

A história subsequente ao aparecimento do readymade é mais complexa do que a simplicidade que o gesto primeiro parecia sugerir. As várias formas pelas quais os artistas contemporâneos retomaram e readaptaram o readymade expressa a complexa estratificação da referência e citação que caracterizam a arte contemporânea, segundo Buskirk. É por isto que além da retomada e readaptação do readymade e o que isto significa, no complexo exemplo da Fountain (after Duchamp) de Levine, Buskirk deslindou também o contexto histórico-social que está refletido na obra da artista. A autoria isola, enquadra e providencia o contexto em que a cópia ou mesmo o objeto encontrado pode ser designado como original. Para Burskirk, a Caixa-Valise que Duchamp passa a produzir em 1941, na qual ele reproduz as próprias obras numa espécie de pequeno museu particular, é significante sobre o tema da reprodução/original. Duchamp volta às suas produções anteriores e as reproduz, porém em menor escala e em outro formato. A obra representaria o "original da cópia”, já que neste caso Duchamp estava realmente confeccionando o objeto que outrora ele apenas deslocara de contexto. E a autora questiona: são cópias? Registros dos originais? "Quando uma cópia é uma réplica e sob quais circunstâncias ela se torna uma obra original?". Para a autora, o impacto de reproduções secundárias na obra de arte é parte de um processo maior de definição entre a cópia e o original, pois nem sempre é óbvio que a cópia não pode coexistir com o original. Quando Duchamp lançou o desafio sobre o objeto de arte original com seus primeiros readymades, a cópia tinha acabado de ser banida dos museus de arte. No entanto, na arte 
contemporânea, como dito anteriormente, não seria antiquado falar em cópia e original como pontas opostas de uma dualidade? O retorno de um artista a seus próprios trabalhos seria considerado uma cópia de si mesmo?

\section{Formas de contingência: do objeto ao contexto}

As tentativas de estender a vida de um trabalho concebido contendo alguma efemeridade em seu contexto darão origem a mudanças espaciais e temporais para os espectadores, que podem ter experiências radicalmente diferentes dependendo de onde e quando um determinado trabalho for encontrado. A ativação do espaço ao redor e do ambiente que serve de contexto para a obra passa a ser fundamental para entender a configuração da arte contemporânea. A maneira pela qual um trabalho é contextualizado, para Buskirk, é mais um dos atos que constituem uma forma de autoria. Assim, um trabalho que é dependente do seu contexto em certo sentido não está finalizado até sua exibição.

Um exemplo importante que a autora cita para mostrar que a autoria pode ser construída através da relação do contexto com a criação e exposição de uma obra é o das "Elipses" de Richard Serra nos anos de 1990 (Torqued Elipse I, Torqued Elipse II e Doubled Torqued Elipse). A autora se refere a uma experiência pessoal dela e revela ter ido ver a obra em três ocasiões diferentes. Ela diz que a experiência do desdobramento dos diferentes espaços esteve completamente ligada à materialidade e tonalidades diferentes das ferrugens na superfície do aço, que se transformavam de acordo com a hora do dia e a luminosidade natural a que estavam expostas no ambiente de exibição. Contando sua experiência com a obra de Serra, Buskirk quer afirmar a premissa de que nenhum trabalho de arte está imune às circunstâncias de sua apresentação, e que esses não estão, na maioria das vezes, dissociados dos arranjos feitos pelo próprio artista. Os "quadros" (frames) formados pelo ambiente ao redor, pelo seu contexto, geram uma forma de contingência que tem profundo impacto em como o trabalho é entendido ou percebido. No caso do trabalho de Serra, a contingência não é o da dissolução do objeto ou ação, mas da forma de percepção que está submetida às experiências de espaço e tempo. E com este objeto que não é "self-contained", mas que depende da relação com seu espaço ao redor, pois se percebe a sensibilidade desse a mudanças mais ambíguas na relação com os componentes ou com seu desenvolvimento, ficando assim mais clara a tal quebra do antigo ideal de unidade na obra de arte. 
A presença do corpo na configuração da arte contemporânea não se dá como uma representação escultural, mas, ao contrário, na pessoa do espectador que se movimenta por meio do espaço marcado pelas formas abstratas. A ênfase de Richard Serra no material, no processo e a complexidade de suas formas move seu trabalho para longe de algumas características, por exemplo, do minimalismo. A percepção visual de seu trabalho não pode ser separada do entendimento corpóreo/físico de sua presença.

\section{A criação de uma situação: recontextualização como uma forma de autoria}

Para muitas formas contemporâneas de arte, entender como um trabalho é realizado inclui mais do que conhecimento dos materiais artísticos e suas propriedades. É aí que reside a ideia cunhada pela autora sobre "original copies", ou seja, obras que parecem cópias de outras obras feitas referenciando a história da arte, readaptadas a novos contextos nos quais são introduzidas, o que muda inteiramente o sentido e a reflexão ali contidos.

O contexto ao qual uma obra será designada é tão marcante que o seu arranjo é constitutivo de uma forma de autoria, bem como de subversão sobre o conceito de originalidade. Buskirk lembra a intervenção de Michael Asher no Art Institute of Chicago na ocasião da $73^{\text {rd }}$ American Exhibition, em 1979, em que o artista transportou a estátua de George Washington do local em que ela ficava no museu para a porta de entrada da galeria devotada às pinturas e artes decorativas europeias do século XVIII. Asher era o autor da situação, não do objeto de arte e dos demais elementos que compunham a situação que ele criou. Com este ato de recontextualização isolado, o artista chamou atenção para a definição do monumento e o impacto da categorização por período e autor; para o processo de preservação e conservação; bem como para distinções entre original e cópia dentro da hierarquia do museu. A realocação da escultura de sua posição original, na entrada do museu, mudou as formas pelas quais a escultura pode ser entendida - como a escultura de um ex-presidente, ligada à história dos Estados Unidos, ou como um trabalho de um escultor específico.

Assim, a questão que se coloca aqui é se, e de acordo com que termos, o conceito de meio é relevante na constituição de uma obra. Como no caso de Asher, em que a autoria paira sobre a recontextualização do espaço.

Uma concepção anterior de meio foi fragmentada, de um lado, em séries de convenções e em abundância de materiais al- 
tamente específicos extraídos de uma multiplicidade de fontes. É neste contexto que a cópia aparece como um modo de produção de arte, como parte de um proceso de reforma que permite a continuação de trabalhos efêmeros de outro modo. Mesmo a determinação sobre o que constitui o trabalho de arte é cada vez menos autoevidente. Uma vez que é aceito que uma obra pode consistir em nada que não seja tangível além da linguagem da declaração ou de uma ação efêmera, o estabelecimento de uma configuração física constitui uma decisão específica e significante que pode ser seguida mais e mais, incluindo a determinação da forma, dos materiais, do contexto e mesmo da duração. Como o objeto físico se tornou cada vez mais instável como um marcador que constitui a obra, a categoria agora muito importante que enquadra e dá sentido a esse jogo de referência é a de autoria artística. Meios e gêneros de arte antigos, típicos de outros momentos da história da arte, como pinturas de paisagem, natureza morta e retrato, fazem suas aparições em pinturas com base em fontes fotográficas. E mesmo a fotografia não é usada como um meio em si mesmo, mas como um suporte para outra finalidade da construção artística. Assim também passa a acontecer com a pintura.

O que mudou com relação à realização desses gêneros tradicionais de arte é a seleção tanto do meio quanto da qualidade pela qual a forma será vista como uma escolha explícita ao invés de um reestabelecimento de formas dadas previamente.

Ao usar fotografias como base para pinturas, como os trabalhos Gerhard Richter, ou no espaço da pintura (como silkscreens de fotos em telas - o suporte tradicional da pintura) como em Andy Warhol', ambos artistas reintroduziram a forma de representação que simultaneamente insiste que a interpretação da representação é em si mesma parte do objeto de trabalho.

A esse respeito eles aludem a processos gerais de reclassificação associada com a entrada da obra de arte no museu, em que retratos anteriores, criados quando este era ainda um gênero voltado para indivíduos específicos, foram realinhados em uma estrutura baseada na autoria. Mas eles puderam ser entendidos em conjunção com muitas referências recentes a retratos que nunca foram parte de um programa para preencher a função tradicional do retrato.

E houve também o contrário: outro exemplo emblemático que a autora cita é a referência ao estilo de pintura "natureza morta" feita por Cindy Sherman em uma de suas séries fotográficas (Untitled \#172, 1987), que emprega adereços baratos e exagerados para chamar atenção à artificialidade do cenário por ela 
montado. O conceito criado por Sherman para suas fotografias e os meios que ela utilizou para isto é que, segundo um crítico de arte, a torna uma artista interessante - e não o fato de ela ser uma boa fotógrafa e ter o domínio das técnicas fotográficas e habilidades de imprimir o material ela mesma.

\section{A designação artística: performance e documentação}

O quadro de autoria que predomina sobre a volta aos readymades e às práticas conceituais deve ser lido como referências conscientes e não uma simples volta a essas práticas por elas mesmas. As formas de autoria frisadas por Buskirk demonstram que um trabalho artístico pode residir ao longo de um continuum de possibilidades.

Os "objetos" contingentes aparecem radicalizados e cheios de paradoxos quando a autora aborda a realização de trabalhos performáticos. Ela indica os exemplos das ações de Adrian Piper e Vitor Acconci, cujos trabalhos foram baseados em apresentações um tanto híbridas: performances muito ligadas à arte conceitual e a outras formas efêmeras conhecidas somente através de documentação. A imediaticidade é improvisada em interações entre o artista e um público insuspeito e desprevenido para recepção da obra.

No caso das performances, sabemos que elas ocorreram porque vimos as figuras (fotos, registros, etc.). Há um "delay" na disseminação do conhecimento sobre o trabalho para uma audiência que teve acesso à atividade apenas por meio de documentações e registros que o artista decidiu providenciar. Assim, a autora volta à questão sobre que tipo de evidências podem ser dadas pela fotografia, que é diferente da experiência em primeira mão do trabalho. A fotografia se junta à ação descrita pelo artista, funcionando junto com a ação.

Buskirk, nos dois trabalhos que descreve, de Piper e Acconci, diz que as ações constituem tipos particulares de performance sem audiência. As ações não foram marcadas e nem anunciadas. As fotografias inesperadamente confirmam o status dessas ações como essencialmente inverificáveis, com parte de seu poder situado no desafio que representam de acreditar que as reivindicações dos artistas tiveram o que eles pediram.

Mesmo fotografias plausíveis dificilmente serviriam de provas de uma atividade, como demonstrou o trabalho Suite vénitienne (1981) de Sophie Calle, em que ela, andando por Paris, escolheu aleatoriamente pessoas para levá-la a partes da cidade 
em que ela normalmente não iria. Na obra The Shadow, também de 1981, a artista inverteu a ordem e pediu a sua mãe para que colocasse um detetive para vigiar suas atividades. Neste tempo, ela dedicou seus dias a uma performance feita para uma única pessoa: o detetive. Ele era, então, mais um participante do que uma sombra de Calle. A estratégia da artista configurou uma inversão da relação entre o padrão de ser seguido ou observado. Quando Calle atua no processo de ser seguida, ela tem a oportunidade de ver a si mesma através dos olhos de outra pessoa nos documentos produzidos. Ambos os trabalhos foram documentados e fotografados, constituindo estes documentos a própria obra.

A questão que Buskirk traz com este exemplo do Sophie Calle que ela aborda é: a fotografia realmente documenta a atividade que ela representa? No caso de Calle, ela pode ser vista também como uma construção ficcional. Por isto, não importa se as fotografias são fato ou ficção, o que é decisivo é o como cada artista decidiu representar seu trabalho. Além do mais, a fotografia representa o trabalho de um artista se isto está dito pelo artista.

Esses trabalhos são sobre a experiência imediata realizada através da presença direta do corpo, mas numa imediaticidade que deve ser imaginada por meio da mediação de documentos. Quanto mais imediato e mais efêmero, mais o trabalho é conhecido apenas através de imagens. Assim, há um espaço temporal construído na recepção da obra entendida em retrospecto, apenas através de documentos das ações inacessíveis - a não ser que o trabalho seja identificado pelo artista não como sendo as ações iniciais, mas os documentos eles mesmos. Esta presença da documentação pode se dar ao menos de três formas: como documento do trabalho, como o documento no trabalho ou tendo o documento como o trabalho.

A perspectiva de que uma atividade pode ser entendida, por meio de documentos ao invés da experiência em primeira mão, tem implicações significativas para a prática contemporânea. Documentos fotográficos cruzam-se com muitos outros meios pelos quais os artistas se manifestam. E a possibilidade da manifestação não ser permanente ou acessível para ser definida como um trabalho tem implicações que se estendem para além do domínio das práticas performáticas. Recordações fotográficas podem prover um tipo particular de acesso à transitoriedade ou a um fenômeno de site-specific que, por essa documentação podem ser entendidas continuamente ao trabalho do artista como um todo, como nas intervenções de Robert Smith.

O que todos os exemplos altamente heterogêneos trazidos por Buskirk em seu livro têm em comum uns com os outros, 
e com um grande número de trabalhos contemporâneos, é a enorme especificidade de cada tomada de decisão pelos artistas. A fragmentação das formas materiais e seus efeitos em elementos cada vez mais separáveis, significa que nenhuma dessas escolhas podem ser entendidas como simplesmente dadas ou usuais. As múltiplas referências a tradições artísticas e à pluralidade de outros recursos permanecem individualmente evidentes mesmo quando a eles são dados uma nova unidade no contexto de trabalho que emerge deste processo. A contingência que permeia a arte contemporânea não é só material, mas também de significado. As formas de conceber a arte são ampliadas ao extremo, assim como a cópia pode ser a base de uma concepção, outras fontes como a referência histórica e a recontextualização de uma situação também podem e são.

\section{Conclusão}

Neste texto busquei aprofundar o debate sobre o entendimento daquilo que temos chamado "arte contemporânea" e utilizei como fio condutor de sua construção os argumentos do livro The contingent object of contemporary art de Martha Buskirk. A discussão levantada por Burskirk e os elementos que ela traz em seu livro vêm complexificar nossa compreensão sobre a arte contemporânea e desdobram a ideia inicial abordada no início do texto, em que apresentei a noção de que faz arte contemporânea aquele que vive seu tempo, como disse a artista Adriana Varejão na ocasião citada acima. Giulio Carlo Argan em Arte e crítica da sociedade (1988) também diz que arte contemporânea é aquela que pretende ser do seu próprio tempo, participando, de alguma forma, da situação política ou cultural presente. E a colocação encontra eco na discussão de Buskirk, quando ela demonstra como a agenda política atual e suas questões vêm à tona em trabalhos que poderiam parecer cópias do tradicional sistema da arte.

The contingent object of contemporary art é o primeiro livro de Martha Buskirk como única autora, pois antes ela já havia lançado como coeditora os livros The Duchamp Effect, em 1996, e The Destruction of Tilted Arc: Documents, em 1990. A historiadora tece seu texto demonstrando todos os seus postulados e hipóteses cuidadosamente através de exemplos. Nestes exemplos, a autora descreve obra, artista e contexto. A descrição detalhada que faz nestes exemplos alonga a leitura e dificulta a chegada ao ponto em que ela demonstra sua hipótese. No entanto, entendendo este tipo de escrita como um estilo, é possível 
dizer que as descrições feitas por Buskirk fazem parte da coesão contida na narrativa de seu texto. Ela nos faz passear por importantes eventos da história da arte de uma forma profunda, detalhada e baseada em experiências muito pessoais, importante para o que tem sido discutido sobre o que podemos entender por arte contemporânea e a "experiência fenomenológica" que ela desencadeia.

Todos os pontos abordados pela autora são fundamentais para compreensão do que pode representar a transformação trazida pelo que tem sido chamado "arte contemporânea" para o status da obra de arte. Ela destaca as inúmeras possibilidades de contingência atreladas ao "objeto" artístico, que são centrais. Entendo que a abstração da materialidade do objeto artístico como aquilo que constitui a obra na contemporaneidade é uma delas - e, por conseguinte, uma das mudanças que caracteriza a passagem da arte moderna à contemporânea. Quando ela dá a seu livro o título de "o objeto contingente da arte contemporânea" e o ilustra em sua capa com a obra "Gnaw" (1992), de Janine Antoni, a primeira associação feita com a qualidade contingente é o da transitoriedade física. No entanto, ainda que isto não seja dito de forma explícita e nem conclusiva pela autora, tanto as descrições de Buskirk, como a teorização pragmática de Heinich que citei, apontaram para o fato de que essa "transitoriedade física" pode ocorrer de inúmeras formas para além da materialidade do objeto.

A arte contemporânea se mostrou no percurso deste texto um fenômeno altamente complexo. E antes de pensar que é preciso fechar a compreensão do fenômeno trabalhado como um rótulo estético, um estilo, um gênero, ou um período histórico, acredito que o papel dos críticos e intelectuais que refletem sobre o mundo da arte seja o de conseguir formular considerações com certo nível de generalidade e complexidade que dê conta de uma realidade tão múltipla. Acredito que só poderemos encontrar uma saída para as inúmeras questões que têm sido colocadas pelos autores citados neste texto à medida que entendermos que expressar a participação no tempo presente é uma tarefa tão múltipla e complexa quanto a de ordenar as situações da vida em seu transcorrer.

\section{NOTAS}

1. Produzido em coautoria com a historiadora Lilia Moritz Schwarcz. O livro foi lançado pela editora Cobogó, em 2014, e no mesmo ano apresentado pelas autoras na Universidade Federal do Rio de Janeiro em encontro promovido pelo PPGSA. 
2. Uma fascinação com a retórica da disposição da exposição, uma análise das condições estabelecidas por diferentes tipos de contexto, a transformação do espaço, e até mesmo a decisão de se mover para fora desses espaços são aspectos deste jogo com a natureza mesma da apresentação. A análise das práticas institucionais tem também encontrado expressão na criação de trabalhos em que o processo de coleta é parte do método do artista, ou onde há um foco explícito na história do objeto. Como parte deste processo, o museu de arte também se tornou um fórum para trabalhos com uma agenda política explícita.

3. Warhol é um dos artistas que Martha Buskirk utiliza amplamente em suas densas descrições. Ele aparece principalmente na discussão sobre as "cópias originais”, mas assim como Duchamp e Donald Judd, ele é um dos artistas centrais e dos mais citados na análise da autora.

\title{
Referências
}

ARGAN, Giulio Carlo. Arte e crítica da arte. Lisboa: Editorial Estampa, 1988.

BARTHES, Roland. A morte do autor. In: O Rumor da Língua. São Paulo: Martins Fontes, 2004.

BENJAMIN, Walter. A obra de arte na era da sua reprodutibilidade técnica. In: Benjamin e a obra de arte: técnica, imagem, percepção. BENJAMIN [et al.]; tradução Marijane Lisboa e Vera Ribeiro; Tadeu Capistrano (Org.). Rio de Janeiro: Contraponto, 2012. BURSKIRK, Martha. The contingent object of contemporary art. Massachussets: Mitpress, 2003.

FOUCAULT, Michel. O que é um autor? (1969) In: Ditos e Escritos - Estética: literatura e pintura; música e cinema. Rio de Janeiro: Forense Universitária, 2006.

HEINICH, Nathalie. Práticas da arte contemporânea: uma abordagem pragmática a um novo paradigma artístico. Sociologia EAntropologia. Rio de Janeiro. v. 04.02:351-372, Outubro, 2014. HUYSSEN, Andreas. Escapando da amnésia - O museu como cultura de massa. In : Memórias do modernismo. Rio de Janeiro: Editora da UFRJ, 1997.

Recebido em: 23/02/15

Aceito: 25/03/15

\author{
PÉROLA MATHIAS \\ perolavcm@gmail.com \\ Doutoranda no Programa de Pós-Graduação em Sociologia e Antro- \\ pologia (PPGSA) na Universidade Federal do Rio de Janeiro (UFRJ) \\ e mestre pela mesma instituição.
}

